\title{
Research on Mine Water Inrush from Rocky Ground Cracks in Shallow Buried Seam in the Condition of Heavy Rain
}

\author{
Che Xiaoyang ${ }^{1,2}$, Hou Enke $e^{1,2, *}$ \\ ${ }^{1}$ School of Geology and Environment, Xi' an University of Science and Technology, Xi'an, China \\ ${ }^{2}$ Geological Research Institute of Coal Green Mining, Xi'an University of Science and Technology, Xi' an, China
}

Email address:

280392042@qq.com (Che Xiaoyang), houek@xust.edu.cn (Hou Enke)

${ }^{*}$ Corresponding author

To cite this article:

Che Xiaoyang, Hou Enke. Research on Mine Water Inrush from Rocky Ground Cracks in Shallow Buried Seam in the Condition of Heavy Rain. Hydrology. Vol. 8, No. 4, 2020, pp. 79-85. doi: 10.11648/j.hyd.20200804.13

Received: November 15, 2020; Accepted: November 24, 2020; Published: December 4, 2020

\begin{abstract}
Mine water inrush from rocky ground cracks is a major form of water inrush from the roof of shallow coal seams in gully areas, especially under heavy rainfall conditions, surface flooding poses a greater threat to the safety of mine production. In order to study the law of mine water inrush from rocky ground cracks in the gully under heavy rainfall conditions in shallow coal seam areas. Take a coal mine in the Carboniferous-Permian system in northern Shaanxi as an example. By predicting the flood flow in the surface gully under different rainfall conditions, summarize and analyze the development characteristics of surface cracks in different working faces, the calculation formula for flood flow of surface channel cracks in shallow coal seam mines is used to predict the water burst at different working faces. Comparing the calculation results of mine water inrush from rocky ground cracks with the actual mine water inrush from rocky ground cracks in surface gully of a certain working face, it is found that the calculated value and the actual water value are small, which can meet the forecast demand of mine water inrush from rocky ground cracks in surface gully. The research results provide a practical method for predicting the amount of mine water inrush from rocky ground cracks in shallow coal seam trenches in the valley area, which can more accurately predict the amount of mine water inrush from rocky ground cracks, which is of great significance to the prevention and control of mine water hazard caused by surface water in shallow coal seam areas.
\end{abstract}

Keywords: Prevention of Mine Water Disaster, Water Inrush, Ground Cracks, Water Inrush Prediction, Calculation Method

\section{Introduction}

Mine water inrush hazards caused by surface water is an important factor restricting the safe mining of shallow coal seams in the valley area. Due to long-term erosion and denudation, the burial depth of coal seams in the valley area is relatively shallow and affected by the disturbance of coal mining, the vertical penetration cracks are easily formed in the overburden strata [1]. If there are perennial flow or seasonal floods in the valley, it is easy to cause water inrush to the underground which water inrush from ground cracks in the surface gully, threatening the safe production of the mine $[2,3]$. The research on the problem of mine water hazard caused by water inrush from ground cracks involves many aspects, including the development law of water-conducting cracks zone caused by coal seam mining, prediction the volume of gully water flow, the law of the volume of water inrush from the ground cracks, and how to prevent it effectively. The water conductivity of the overlying bedrock of a shallow coal seam is determined by two factors, the development characteristics of cracks and the water-resistance of the rock formation, which are mutually exclusive. The fissures formed by coal mining are the direct cause of surface runoff inrush into the underground of shallow coal seams in the valley area. The development characteristics and development rules of the fissures are the main factors affecting the law of water inrush from the ground runoff flow through the fissures. The form of penetrating fissures is that the descending fissures on the surface and the upward fissures of the overburden struck through [4], or the overburden stepped collapse due to combined tensile and shear failure, forming a cut-out step [1, 5]. Regardless of the form of the through fissure, it is 
determined by the buried depth and mining thickness of the coal seam $[4,6]$. There is a positive correlation between the width and depth of ground cracks [7]. When the push-mining position of the working area passes through the area directly below the valley, the overlying rock fractures are developed most violently, and the surface runoff is most likely to inrush into the well. As the coal seam push-mining position pass-through the valley, the settlement of the overlying rock gradually stabilizes, the fissures in the overlying rock gradually change from large to small, the water-permeability of the overlying rock decreases, and the amount of water inrush from ground cracks decreases [8]. Based on the predicted gully flood flow and mine drainage capacity, and combined with the damage of the overlying rock on the roof of the coal seam, Yan partition predicted the risk of water inrush from the ground cracks [9]. Chen classified the types of mine water inrush hazards caused by surface flow in the loess area, and proposes the principle of mine water inrush and sand collapse under runoff and a differentiated mine water hazard management models [10]. Hou obtained the influencing factors of mine water inrush from ground cracks in gully and the theoretical calculation method of the volume of it through laboratory experiments [11]. Some scholars have also put forward some corresponding treatment measures for the problem of mine water inrush from ground cracks. Combining ground topography and landform features to carry out surface filling and excavation and drainage measures to prevent mine water inrush caused by surface water [12]. Use different crack backfilling methods to fill the surface cracks developed area [11]. Reserve a waterproof coal pillar of reasonable size under the river valley to ensure the stability of the water-proof soil layer [13, 8]. Such measures can effectively prevent surface runoff from entering the mine through the through fissures in low-lying areas.

However, there are still problems that the calculation method of the actual mine water inrush from ground surface is not perfect, and the prediction of the actual volume of mine water inrush is not accurate enough. Engineering treatment measures for mine water inrush from ground cracks hazards are usually implemented under the premise of non-quantitative research. Therefore, it is necessary to predict the volume of mine water inrush from ground cracks through experiments and theoretical calculations based on the actual geological characteristics of the valley and local rainfall data. It can provide reasonable prevention and control measures for the subsequent mining of the working face, and can also provide reference for the prevention and control of mine water hazards in other areas of the same type.

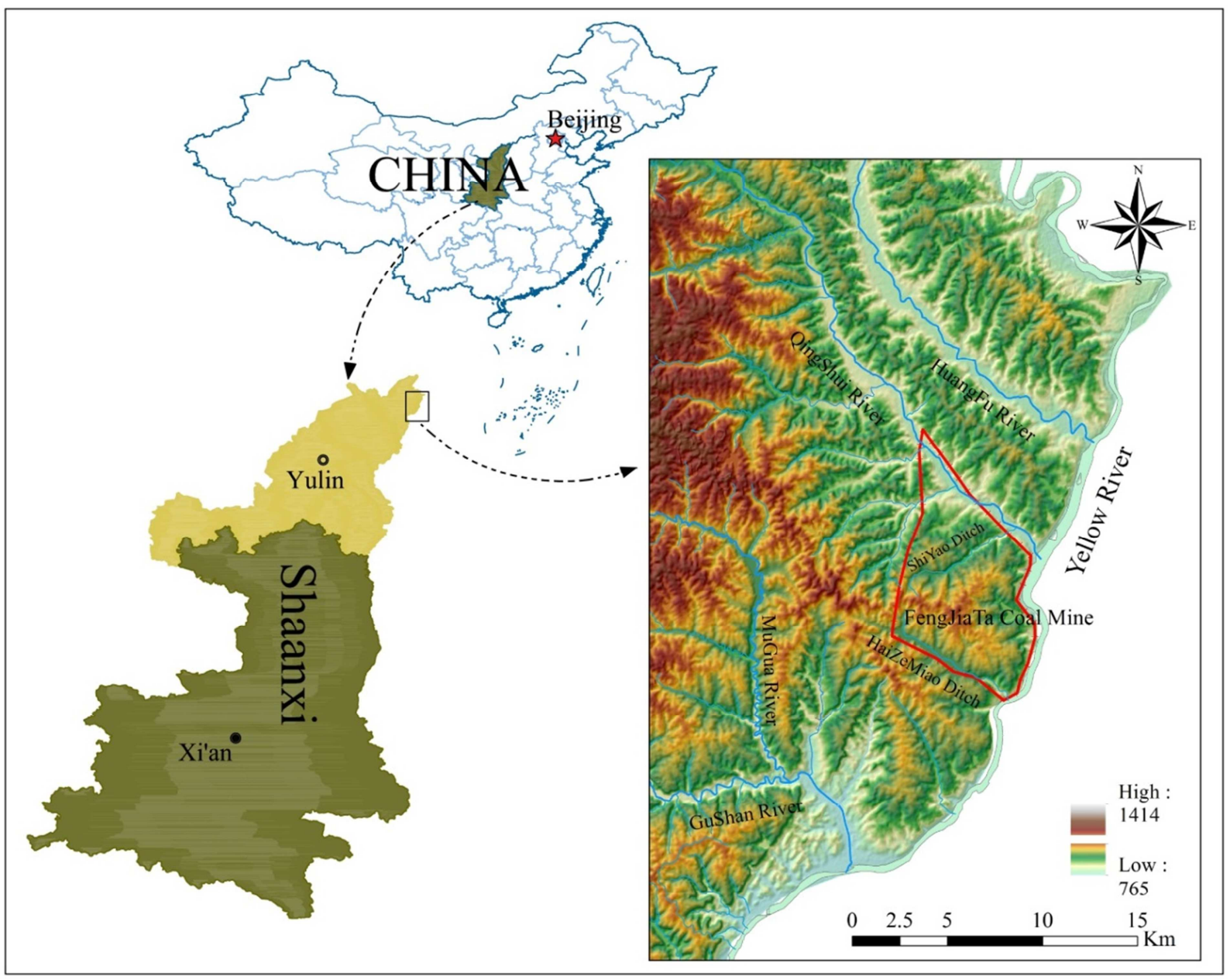

Figure 1. Distribution of the study area. 


\section{Overview of the Study Area}

Fengjiata Coal Mine belongs to the Fugu Carboniferous-Permian coal mining area in China. It is located in the northern part of the Loess Plateau. The ground is covered by Quaternary sediments, which is a typical loess mountain ridge landform. This area belongs to typical temperate semi-arid continental climate, with less rainfall and concentrated rainfall, generally concentrated in July September annually, with annual average rainfall between $400 \sim 420 \mathrm{~mm}$. The water system in the study area is widely distributed. The Yellow River flows from north to south from the east of the coal mine field. The perennial rivers Qingshui River and Haizemiao River merge into the Yellow River from west to east from the north and south boundaries of the coal mine field respectively. The gullies in the coal mine field are widely distributed, and the rocks in the valley are exposed. One of the gullies, Shiyao Gully, traverses the coal mine field from southwest to northeast and finally merges into the Qingshui River (Figure 1). There is no perennial flow in the gully, however, it is easy to form mountain torrents with short duration and large water volume in rainy season.
The structure is simple in mine field which is inclined to north west and produces relatively gentle shape. From old to new, the exposed strata in the area mainly include Carboniferous, Permian, Triassic, Jurassic, Cenozoic Neogene and Quaternary. The main water-resistant strata in the coal mine field are laterite strata in Baode Formation and mudstone layer in Benxi Formation. The main mineable coal seams are No. 2,4 , and 8 coal seams. The No. 2 coal seam is located in the upper part of Shanxi Formation, with a thickness of $1.2-5.3 \mathrm{~m}$ and an average of $3.1 \mathrm{~m}$. It is the first mineable coal seam in the area (Figure 2). 1201 working face is the first mining working face in the coal mine field, and the main mining is the No. 2 coal seam. Shiyao Gully is located on the ground surface above the 1201 working face, and the horizontal projection is oblique to the working face. 1201 working face to 1204 working face are distributed side by side on the plane. The buried depth of these working faces in Shiyao Gully area is $16 \sim 60 \mathrm{~m}$, and there is lack of effective water-resisting strata in overlying strata on the coal seam. The overburden of the coal seam is prone to form water-conducting through fissure after being affected by mining.

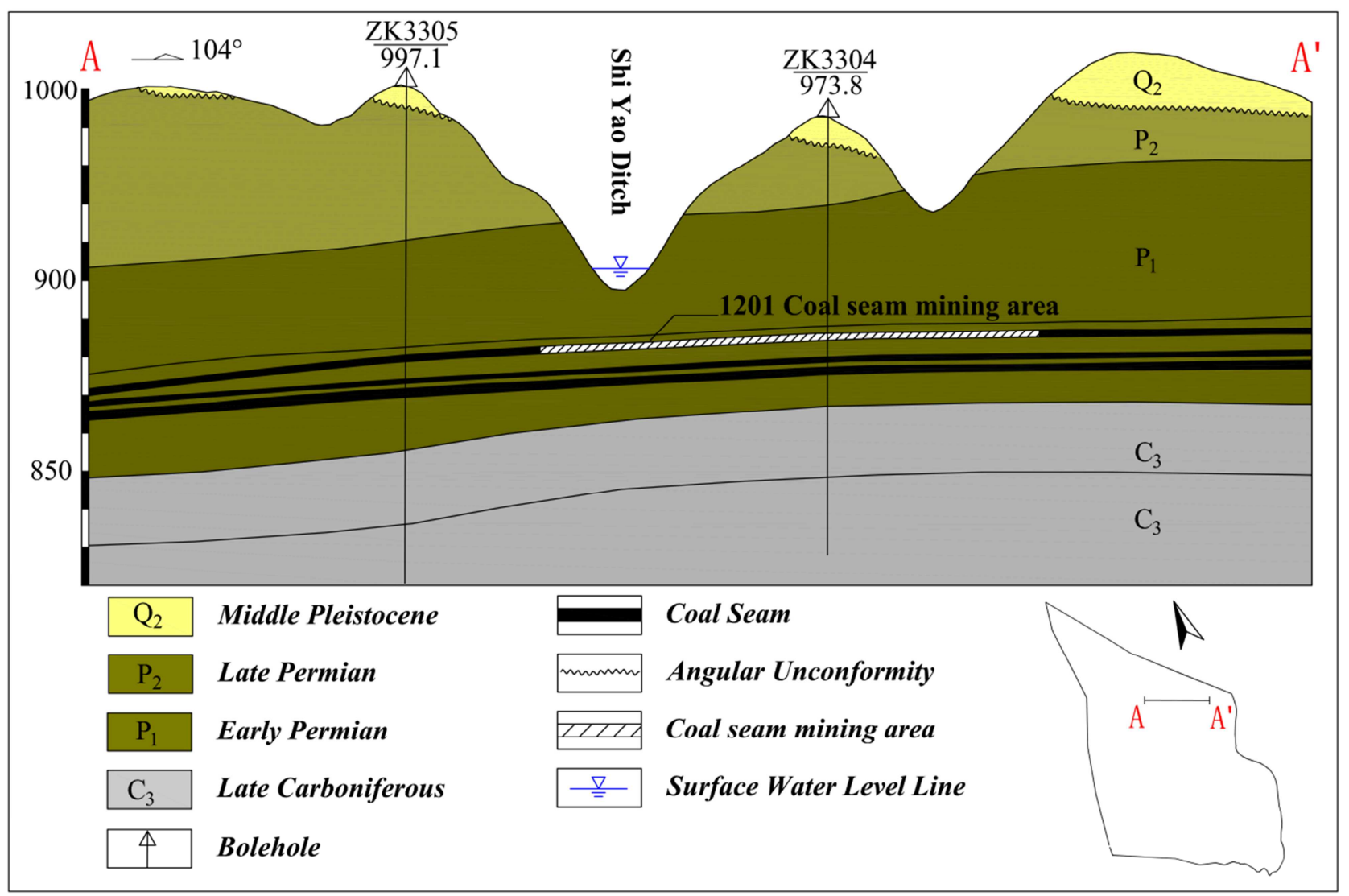

Figure 2. Minefield stratigraphic structure map.

\section{Influencing Factors of Water Inrush from Ground Cracks}

Mine water inrush from ground cracks is mainly affected by two factors: source of water inrush and water-conducting fissure channels. The water-conducting fissure channels is a prerequisite for mine water inrush from ground cracks, source of water inrush is another necessary condition for water inrush from ground cracks. These two conditions are 
indispensable, and together affect the characteristics of mine water inrush from ground cracks.

The water-conducting fissure channels refers to the through fissure formed by mining disturbance in overburden strata of coal seam. Its characteristics are mainly affected by factors such as the buried depth of the coal seam, the thickness of the coal seam, the structure of the overburden and the landform characteristics.

According to field survey data, the gully section where the gully azimuth is perpendicular to the mining direction of the working face, the damage of the ground surface is mainly the surface uplift, and there are not many cracks. The gully section where the gully azimuth is consistent with the mining direction of the working face has many cracks in the ground surface.

The characteristics of mine water inrush from ground cracks is affected by the surface water source conditions and the coal roof crack conditions. Compared with other types of mine water inrush hazards, the source of the mine water inrush and the channel of the water conducting fissure are clear. The source of mine water inrush mainly comes from surface runoff and seasonal flooding in the gully, and the water flow can be obtained through field measurement or theoretical calculation. The water-conducting fissure channel is mainly formed in the roof of the coal seam to connect the ground surface and the goaf after mined. The characteristics of fissures can also be obtained through field investigation. However, due to the lack of measured data on the volume of mine water inrush from ground cracks for a long time, there is no conclusion on the regularity of mine water inrush formation in the surface gully.

\subsection{Water Flow in the Gully}

The rainy season precipitation in northern Shaanxi is obviously bimodal, and the hourly extreme heavy rainfall threshold is greater than $8 \mathrm{~mm} / \mathrm{h}$ [14], The maximum daily precipitation in the past 50 years is $49.3 \sim 57.2 \mathrm{~mm} \mathrm{[15].} \mathrm{By}$ comparing and analyzing the historical flood level flow results of field surveys and different theoretical flood flow results, obtain the empirical theoretical calculation formula (Equation. 1) in line with actual flood flow. Calculate the flood flow in the study area once in 20 years.

$$
Q_{5 \%}=0.009 F^{0.74} J^{0.32} H_{6 \mathrm{p}}{ }^{1.30}
$$

where $Q_{5 \%}$ is the once-in-20-year flood flow, $\mathrm{m}^{3} / \mathrm{s} ; F$ is the basin area, $\mathrm{km}^{2} ; J$ is the average gradient of the main gully, $\% ; H_{6 \mathrm{p}}$ is the heavy rainfall with a design frequency of $6 \mathrm{~h}, \mathrm{~mm}$.

Based on the surface elevation data in the study area, use ArcGIS hydrological analysis tools to divide the surface watershed and determine the watershed range of Shiyao Gully (Figure 3). It is obtained that the watershed area up to the 1201 working face in the Shiyao Gully watershed is 8.00 $\mathrm{km}^{2}$.

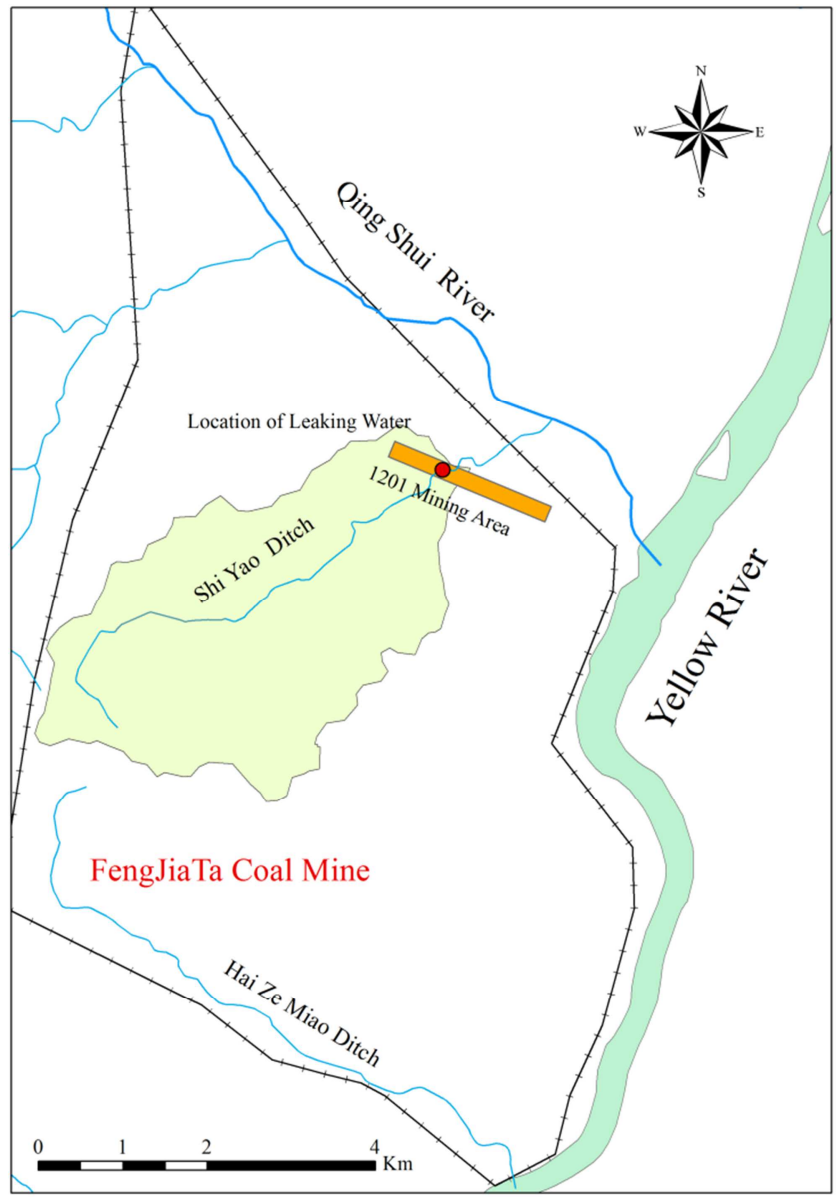

Figure 3. Watershed distribution map of the study area.

Using the same method, we get that the watershed area up to the 1202 working face in the Shiyao Gully watershed is $7.50 \mathrm{~km}^{2}$, the watershed area up to the 1203 working face is $6.7 \mathrm{~km}^{2}$, and the watershed area up to the 1204 working face is $6.3 \mathrm{~km}^{2}$. The main gully slope gradient of Shiyao Gully is about 4\%o 7\%o. When calculating the flood flow, we can use the average gully slope gradient $5 \%$ o for calculation.

Combining the hourly extreme heavy rainfall threshold and the maximum daily rainfall. Using the rainfall threshold value and the maximum daily rainfall value under heavy rainfall conditions to calculate the maximum rainfall value in 6 hours, the maximum rainfall range under 6 hours heavy rainfall conditions is $48 \mathrm{~mm} \sim 57.2 \mathrm{~mm}$.

We bring rainfall data, watershed area data, and the average gradient of the main gully into Eq. 1, and calculate the flood flow value at different locations in Shiyao Gully, the final results are shown in Table 1.

Table 1. Flood flow calculation value.

\begin{tabular}{|c|c|c|c|c|}
\hline & $1201\left(\mathrm{~m}^{3} / \mathrm{s}\right)$ & $1202\left(\mathrm{~m}^{3} / \mathrm{s}\right)$ & $1203\left(\mathrm{~m}^{3} / \mathrm{s}\right)$ & $1204\left(\mathrm{~m}^{3} / \mathrm{s}\right)$ \\
\hline Maximum daily rainfall conditions & 13.51 & 12.88 & 11.85 & 11.30 \\
\hline $6 \mathrm{~h}$ extreme heavy rainfall & 10.76 & 10.26 & 9.44 & 9.00 \\
\hline
\end{tabular}




\subsection{Features of Cracks in Gully}

We used drone remote sensing and manual field survey methods to investigate the distribution of ground surface fissures in the Shiyao Gully watershed. The stratigraphic structure and coal seam structure characteristics in the study area are stable, and the coal seam mining thickness is basically the same, and they are located in the same watershed. Therefore, the field survey results have certain reference significance for predicting the characteristics of ground surface fissures after mining in other working faces in the same area.

The azimuth of Shiyao Gully and the strike direction of the research working face obliquely intersect on the horizontal projection. The gully flows through the working face area in an "S" shape. Due to the twists and turns of the gully, the angle between it and the direction of the working face is not constant. Therefore, some sections are approximately perpendicular to the direction of the working surface, and some sections are approximately parallel to the direction of the working surface.

According to the actual observations in the field, the ditch section where the azimuth of the gully is perpendicular to the strike direction of the working face is squeezed by the mountains on both sides, and the fissures are not many. There are a few fissures at the bottom of the gully where the azimuth angle of the gully is parallel to the direction of the working face, the fissures width is about $0 \mathrm{~cm}-5 \mathrm{~cm}$, and the fissures spacing is $3 \mathrm{~m}-5 \mathrm{~m}$. There are also a small number of through fissures in the overlying rock above the air-return roadway and the haulage roadway. Generally, the width of the fissures is wider, about $10 \mathrm{~cm} \sim 20 \mathrm{~cm}$, but the number of fissures is relatively small. Number of ground surface fissures are shown in Table 2.

The fissures width data can be divided into 6 groups according to the actual situation. For the convenience of calculation, the average width of each group is taken during the calculation. The number of fissures is consistent with the actual number, and the gully slope gradient is consistent with the original gully slope gradient.

The main coal seam of 1201 working face is No. 2 coal seam, and the average thickness of No. 2 coal seam is $3.1 \mathrm{~m}$. The incline width of coal seam mining face is about $240 \mathrm{~m}$. The coal seam overburden is mainly sandstone of the Lower Shihezi Formation of the Permian. The seam floor elevation is about $855 \mathrm{~m}$. The elevation of the bottom of Shiyao gully is $875 \sim 912 \mathrm{~m}$. The 1201 working face is located at the end of the gully, and the ground elevation is the lowest. The coal seam buried depth in the valley area are shown in Table 3.

Table 2. Statistical table of Number of ground surface fissures.

\begin{tabular}{lllll}
\hline fissures width/mm & $\mathbf{1 2 0 1 / \text { Amount }}$ & $\mathbf{1 2 0 2 / \text { Amount }}$ & $\mathbf{1 2 0 3 / \text { Amount }}$ & $\mathbf{1 2 0 4 / \text { Amount }}$ \\
\hline $1 \sim 10$ & 7 & 11 & 8 & 10 \\
$10 \sim 20$ & 4 & 5 & 4 & 3 \\
$20 \sim 30$ & 4 & 1 & 3 & 3 \\
$30 \sim 40$ & 2 & 2 & 1 & 1 \\
$40 \sim 50$ & 1 & 2 & 0 \\
$50 \sim 60$ & 0 & 0 & 0 & 1 \\
\hline
\end{tabular}

Table 3. Buried depth of coal seam.

\begin{tabular}{lllll}
\hline & 1201working face & 1202working face & 1203working face & 1204working face \\
\hline Depth $(\mathrm{m})$ & $17-27$ & $30-35$ & $36-43$ & $49-54$ \\
\hline
\end{tabular}

\section{Forecast of Mine Water Inrush from Ground Surface}

\subsection{Calculation of Mine Water Inrush}

After obtaining the flow data of the gully and quantity data of the ground surface fissures of the area to be predicted, we can use the prediction method proposed by Hou to predict the volume of mine water inrush from ground surface in different working faces (Hou et al., 2020).

Hereinafter, the methods for predicting the volume of mine water inrush from ground surface are collectively referred to as methods. Unless otherwise specified, the method below refers to the method of predicting the volume of mine water inrush from ground surface.

Since the prediction method is proposed on the basis of a unit width gully. It is necessary to convert the geometric scale and flow scale according to the characteristics of the actual gully in the actual mine water inrush prediction application.

Firstly, calculate the geometric proportional relationship between the actual gully width and the unit gully width $(1 \mathrm{~m})$. The profile of Shiyao Gully is "U"-shaped, and the width of the bottom of the research section is about $4.0 \mathrm{~m}$. We take the average value of $4.0 \mathrm{~m}$ in the actual calculation.

The geometric ratio between the actual gully and the unit width gully is obtained by using the geometric ratio principle in open channel hydraulics. The geometric ratio of the actual gully to the single-wide gully is $\lambda_{\mathrm{L}}=\mathrm{L} / 1=4.0 / 1.0=4$. And also the flow ratio between the actual gully and the unit width gully can be obtained by using the flow ratio principle in open channel hydraulics. The flow ratio of the actual gully to the single-wide gully is $\lambda_{\mathrm{Q}}=\lambda_{\mathrm{L}} 2.5=42.5=32$.

Firstly, use the calculation equation of the volume of mine water inrush from single fissure in the prediction method (Equation 2) to calculate the actual mine water inrush from 
single fissure.

$$
q_{p}=\frac{1}{3} \lambda_{Q} \frac{9}{10}\left(\frac{B}{\lambda_{L}}\right)\left(\frac{Q_{p}}{\lambda_{Q}}\right)^{1 / 2} \log \left(\frac{1}{J}\right)
$$

where $q_{p}$ is the volume of the water inrush from the single fissure; $\lambda_{Q}$ is the flow ratio between the actual gully and the unit width gully; $\lambda_{L}$ is the geometric ratio between the actual gully and the unit width gully; $B$ is the width of the fissure; $Q_{p}$ is the total water flow in the gully; $J$ is the slope gradient of the gully.

If the number of fissures in the actual gully is small, we can use Equation 2 to calculate the mine water inrush from the each fissure, and then sum them, the actual mine water inrush from ground surface in the gully can be obtained.

According to the field survey results, the distribution and number of ground surface fissures in Shiyao Gully are obtained, and they are grouped according to the width interval of fissure, as shown in Table 2. Get the number of groups (n), and count the number of fissures (m1, m2, m3...) in each group. When calculating the volume of the water inrush from the ground surface, take the average width of each group of fissures for calculation. Multiply the calculated volume of mine water inrush from the ground surface of each single fissure by the number of fissures in each group, and then sum the volume of mine water inrush of different groups of fissures to obtain the corresponding inrush water volume of the actual working face. The actual calculation process is show in Equation 3.

$$
q_{p}{ }^{\prime}=\frac{1}{3} \sum_{i=1}^{n} m_{i} q_{p}=\frac{1}{3} \sum_{i=1}^{n} m_{i} \lambda_{Q} \frac{9}{10}\left(\frac{B_{i}}{\lambda_{L}}\right)\left(\frac{Q_{p}}{\lambda_{Q}}\right)^{1 / 2} \log \left(\frac{1}{J}\right)
$$

where $q_{p}$ ' is the volume of the mine water inrush from the total fissures; $n$ is the number of groups of fissures; $m_{i}$ is the number of fissures in the ith group; $\lambda_{Q}$ is the flow ratio between the actual gully and the unit width gully; $\lambda_{L}$ is the geometric ratio between the actual gully and the unit width gully; $B_{i}$ is the average width of the ith group of fissures; $Q_{p}$ is the total water flow in the gully; $J$ is the slope gradient of the gully.

The gully flow volume $Q_{p}$ has been obtained through the rainfall data and flood flow empirical formula in the study area. The detailed data is shown in Table 1 . The size of the fissure width $B$ has been measured in the field. The detailed data is shown in Table 2. Take the total water flow data calculated in Table 1 and the measured fracture data obtained in Table 3 into Equation 3. The slope gradient of the gully $(J)$, the geometric ratio $\left(\lambda_{L}\right)$, and the flow ratio $\left(\lambda_{Q}\right)$ are also take into Equation 3. And the volume of the mine water inrush from the fissures at different locations in the gully can be calculated.

Table 4. The volume of the mine water inrush from the fissures.

\begin{tabular}{lllll}
\hline & $\mathbf{1 2 0 1}\left(\mathbf{m}^{\mathbf{3}} / \mathbf{h}\right)$ & $\mathbf{1 2 0 2}\left(\mathbf{m}^{\mathbf{3}} / \mathbf{h}\right)$ & $\mathbf{1 2 0 3}\left(\mathbf{m}^{\mathbf{3}} / \mathbf{h}\right)$ & $\mathbf{1 2 0 4}\left(\mathbf{m}^{\mathbf{3}} / \mathbf{h}\right)$ \\
\hline Max & 4004.52 & 3973.10 & 3629.46 & 3071.66 \\
Minimum & 3573.79 & 3546.05 & 3239.43 & 2741.30 \\
\hline
\end{tabular}

Table 4 shows the data of volume of the mine water inrush from the fissures at different locations in the gully of the study area. The rainfall data used in the calculation is the largest daily rainfall data in 50 years, so the calculated the data of the mine water inrush from the fissures is often larger than the actual value.

\subsection{Verification of Actual Data}

In August 2009, there was a sudden heavy rain in the study area, which lasted 1 hour and 30 minutes, and the total rainfall reached $40 \mathrm{~mm}$. There is mountain torrents were formed in Shiyao Gully, and the flood destroyed the previous treatment project. Flood water flows into the underground mine along the through fissures above the 1201 working face. The volume of the mine water inrush in the mine is gradually increasing, the maximum water volume reaches $3000 \mathrm{~m}^{3} / \mathrm{h}$, and the total volume of the mine water inrush is about $14,600 \mathrm{~m}^{3}$. This incident caused a flooding accident. Based on the rainfall data this time and Equation 1, it can be calculated that the maximum flood flow in Shiyao Gully is $8.5 \mathrm{~m}^{3} / \mathrm{s}$, or $30600 \mathrm{~m}^{3} / \mathrm{h}$.

Take the calculated total water flow in the gully and the data of the fissures in the 1201 working face area of Shiyao Gully into Equation 3, and the volume of the mine water inrush from the fissures were calculated is $3319.8 \mathrm{~m}^{3} / \mathrm{h}$. The calculated mine water inrush is very close to the actual mine water inrush value in the mine, which shows that the theoretical calculation formula obtained by Equation 3 is feasible. The working method and the mine water inrush from the fissures prediction method described in this article can be used to predict the mine water inrush in the shallow coal seams.

\section{Conclusion}

The characteristics of mine water inrush from ground fissures are mainly determined by the total water flow in the gully and the characteristics of ground through fissures.

When the coal seam working face crosses the gully, the ground fissures in the gully section perpendicular to the working face strike are few, and this section of the gully is generally pushed by the mountains on both sides to form a surface uplift. The ground fissures in the gully section parallel to the working face strike are many, and the width of the fissures is larger.

Using the working method of the mine water inrush from the fissures and the prediction equation of the mine water inrush in the article, the volume of the mine water inrush from the total fissures under the condition of heavy rainfall can be predicted more accurately.

\section{References}

[1] FAN Gangwei, ZHANG Dongsheng, MA Liqiang. Overburden movement and fracture distribution induced by longwall mining of the shallow coal seam in the Shendong coalfield [J]. Journal of China University of Mining \& Technology, 2011, 40 (2): 196-201. 
[2] WU Xiong, YU Qingchun, WANG Xiaogang, et al. Exploitation of coal resources under surface water body [J]. Chinese Journal of Rock Mechanics and Engineering, 2006 (05): 1029-1036.

[3] HOU Enke, FENG Dong, XIE Xiaoshen, et al. Study on Development Characteristics and Treatment Methods of Mining Surface Cracks in shallow-buried Coal Seam Gully [J/OL]. Journal of China Coal Society, 1-13 [2020-06-10]. https://doi.org/10.13225/j.cnki.jccs.2020.0143.

[4] Huang Qingxiang. Research on roof control of water conservation mining in shallow seam [J]. Journal of China Coal Society, 2017, 42 (1): 50-55.

[5] XUE Dongjie, ZHOU Hongwei, REN Weiguang, et al. Stepped shearing-induced failure mechanism and cracks propagation of overlying thin bedrocks in shallow deep coal seams mining [J]. Journal Of China Coal Society, 2015, 40 (08): 1746-1752.

[6] LI Peng. Study on Fracture Development characteristic and Prevention Mechanism of Runoff Flood induced by Thick Seam Mining under Valleys [D]. Xuzhou: China University of Mining and Technology, 2015.

[7] LIU Hui, The Development Law and Treatment Technology of Ground Fissures due to Underground Mining in Loess Hilly Area of Western China [D]. Xuzhou: China University of Mining and Technology, 2014.

[8] ZHANG Jie, YANG Tao, WANG Bin, et al. Prediction analysis of roof water-inrush in shallow coal seam with surface valley runoff [J]. Journal of Mining \& Safety Engineering, 2017, 34 (05): 868-875.
[9] YAN Chaobo. Research on Forecast of water bursting risk zoning on roof coal in Zhang Jia mao Mine [D]. Xi'an: Xi'an University of Science and Technology, 2013.

[10] CHEN Wei. Study on Mechanism and Control Technology of Mining Water Disasters under Loess Gully Runoff in Northern Shaanxi [D]. Xuzhou: China University of Mining and Technology, 2015.

[11] HOU Enke, CHE Xiaoyang, LONG Tianwen, et al. Research on prediction method of water inrush from ground cracks in shallow buried seams [J/OL]. Journal of China Coal Society, $1-11$ [2020-06-10]. http://kns.cnki.net/kcms/detail/11.2190.TD.20200409.1036.00 6.html.

[12] ZHANG Shunfeng, HU Ruilin, WU Xiong. Dynamic prediction of ground deformation and drainage design for shallow thick coal seam mining [J]. Journal of China Coal Society, 2012, 37 (Supplement 2): 301-306.

[13] ZHANG Guanglei, JU Jinfeng, XU Jialin. Influence of longwall mining on surface runoffs in gully terrain area [J]. Journal of China Coal Society, 2016, 41 (05): 1219-1226.

[14] CAI Xinling, YE Dianxiu, SUN Xian, et al. Hourly Precipitation Variability Features in Shaanxi Province in Flood Season during 1961-2011 [J]. Plateau Meteorology, 2014, 33 (06): 1618-1626.

[15] WANG Tao, YU Dongxue, YANG Qiang. Characteristics of spatial-temporal change of precipitation in loess plateau area of northern Shaanxi [J]. Journal of Water Resources \& Water Engineering, 2014, 25 (06): 24-28+33. 